\title{
Perancangan dan Pembuatan Sistem Informasi Gudang (Studi Kasus : PT. PLN (Persero) Area Surabaya Barat)
}

\author{
Budi Prasetyo \\ Program Studi Sistem Informasi \\ Institut Informatika Indonesia \\ budipras@pln.co.id
}

\author{
Timothy John Pattiasina \\ Program Studi Manajemen \\ Informatika \\ Institut Informatika Indonesia \\ temmy@ikado.ac.id
}

\author{
Anggya Nanda Soetarmono \\ Program Studi Sistem Informasi \\ Institut Informatika Indonesia \\ anggya@ikado.ac.id
}

\begin{abstract}
Abstrak-Sistem informasi berbasis komputerisasi merupakan salah satu faktor penting bagi perusahaan perusahaan dalam mengelola segala aktifitas perusahaan. Bahkan penggunaan teknologi komputer tersebut akan menjadi syarat utama untuk menunjukkan kualitas suatu bidang dan menjadi modal terpenting dalam memenangkan persaingan. Sistem Informasi Gudang di PT. PLN (Persero) Area Surabaya Utara dibangun karena masih menggunakan cara manual untuk melakukan penerimaan barang datang, permintaan barang, dan pemberian barang, sehingga mempengaruhi dalam pelaksanaan operasional kerja, baik dalam segi kecepatan, pelayanan, dari segi informasi yang dihasilkan. Untuk itu diperlukan suatu sistem yang dapat memudahkan manajemen dalam mengelola seluruh aktifitas yang ada di gudang.

Sistem Informasi Gudang PT.PLN (Persero) Area Surabaya Utara adalah suatu sistem yang mengelola data barang, data rayon, dan transaksi yang ada di gudang. Sistem ini menggambarkan rangkaian kegiatan dari mulai mengelola barang datang, permintaan barang, barang keluar hingga pelaporannya.

Setelah melalui tahapan analisis dan implementasi, kemudian dilakukan tahapan selanjutnya yaitu tahap pengujian sistem dimana pengujian ini menggunakan metode pengujian white box yang berfokus pada pengujian perangkat lunak. Dari hasil pengujian, dapat ditarik kesimpulan bahwa Sistem Informasi Gudang di PT.PLN (Pesero) Area Surabaya dibangun untuk mempermudah manajemen dalam melakukan pengawasan dan pengendalian di gudang.
\end{abstract}

Kata Kunci : Gudang, PLN Surabaya Utara, Perusahaan, Manajemen

\section{PENDAHULUAN}

PT. Perusahaan Listrik Negara (Persero) Area Surabaya Utara adalah perusahaan instansi pemerintah yang bergerak dibidang jasa kelistrikan. Dalam melayani pendistribusian tenaga listrik ke pelanggannya dimana data jumlah pelanggan hampir mencapai 320 ribu pelanggan yang tersebar di 6 (enam) Rayon/Unit. Dalam Rencana Jangka Panjang tahun 2013 - 2017 yang diputuskan oleh manajemen salah point pentingnya adalah kecepatan pelayanan penyambungan dan gangguan. Untuk dapat memenuhi tuntutan tersebut salah satunya diperlukan ketersediaan barang di gudang.

Gudang merupakan tempat penyimpanan barang yang dibutuhkan oleh semua perusahaan. Hal tersebut juga terjadi di PT. PLN (Persero) Area Surabaya Utara, barang yang disimpan di gudang tersebut antara lain KWH Meter (APP), pembatas MCB, kabel, kotak KWH Meter (APP), tiang, traverest, arrester dan masih banyak lagi barang pendukung lainnya yang tidak bisa disebutkan oleh penulis karena hampir 400 jenis barang. Dimana barang-barang tersebut tersimpan di 2 (dua) gudang yang cukup besar yaitu gudang A mempunyai ukuran $+/-1200 \mathrm{~m}^{2}$ dan gudang B mempunyai ukuran $+/-800 \mathrm{~m}^{2}$.

Dalam mengelola gudang tersebut PT. PLN (Persero) Pusat telah memakai SAP sebagai sistem utama.Akan tetapi dalam penerapannya, di sistem utama SAP tidak sesuai dengan kondisi kenyataan lapangan yg ada seperti proses waktu pengadaan barang lama dimana membutuhkan ratarata 3 bulan atau bahkan lebih. Hal ini bertetangan dengan permintaan barang dilapangan yang bersifat darurat dan mendesak yang membutuhkan hitungan harian bahkan hitungan jam. Untuk mengatasi permaslahan tersebut perlu dibuatkan aplikasi pendukung guna menjembatani sistem SAP dengan kondisi lapangan yang bersifat mendesak.

\section{METODOLOGI PENELITIAN}

Mengacu pada latar belakang masalah tersebut maka penulis berkeinginan untuk membuat tugas akhir yang dituangkan dalam judul "Perancangan dan Pembuatan 
Sistem Informasi Gudang" Studi Kasus pada PT. PLN (Persero) Area Surabaya Utara ". Dengan dilakukannya penelitian ini diharap dapat membantu mencatat dan mempercepat semua transaksi yang terjadi di gudang serta memudahkan dalam pengawasan keluar masuknya barang. Sedangkan landasan teori yang mendasari penelitian perancangan dan pembuatan sistem ini akan dijelaskan padasub-bab berikut ini:

\section{A. Sistem Informasi}

Data dan informasi sangat berkaitan dengan pengertian dari sistem informasi sebagai entias penting pembentuk sistem informsi. Data merupakan nilai, keadaan atau sifat yang berdiri sendiri dan terlepas dari konteks apapun. Sementara sistem informasi adalah data yang telah diolah menjadi sebuat bentuk yang berarti bagi penerimanya dan bermanfaat dalam pengambilan keputusan saat ini atau mendatang. Sedangkan definisi lain informasi adalah data yang telah diproses atau data yang memiliki arti.

Sistem informasi mempunyai 3 (tiga) konsep yaitu:

- Input

- Proses

- Output

Konsep berawal dari input data yang mengalami pemrosesan dan pada akhirnya mengerluarkan hasil berupa output data.

\section{B. Database Management System(DBMS)}

Sistem manajemen database atau database management system (DBMS) adalah merupakan suatu sistem software yang memungkinkan seorang user dapat mendefinisikan, membuat, dan memelihara serta menyediakan akses terkontrol terhadap data. Database sendiri adalah sekumpulan data yang berhubungan dengan secara logika dan memiliki beberapa arti yang saling berpautan.

Keuntungan dari Database Management System adalah:

- Pengulangan Data Berkurang.

Pengulangan data atau repetisi berarti bahwa kolom data yang sama (misal: alamat seseorang) muncul berkali-kali dalam file yang berbeda dan terkadang dalam format yang berbeda. Dalam sistem pemrosesan yang lama, file - file yang berbeda akan mengulang data yang sama sehingga memboroskan ruang penyimpanan.

- Intregitas Data Meningkat.

Integritas tidak akurat. dalam DBMS, berkurangnya pengulangan berarti meningkatkan kesempatan integritas data, karena semua perubahan hanya dilakukan di satu tempat.

- Keamanan Data Meningkat. Meskipun berbagai departemen bisa berbagi pakai data, Namun akses ke informasi bisa dibatasi hanya untuk pengguna tertentu. Hanya dengan menggunakan password maka informasi finansial, medis, dan nilai mahasiswa dalam database sebuah universitas tersedia hanya bagi mereka yang memiliki hak untuk mengetahuinya.

- Kemudahan Pemeliharaan Data.

DBMS menawarkan prosedur standar untuk menambahkan, mengedit dan menghapus rekaman, juga untuk memvalidasi pemeriksaan untuk memastikan bahwa data yang tepat sudah dimasukkan dengan benar dan lengkap ke dalam masing - masing jenis kolom.

\section{Intranet}

Intranet adalah jaringan komputer pribadi yang menggunakan protokol internet untuk dapat berbagi data dan informasi secara aman dalam lingkup satu organisasi atau badan usaha. Intranet juga sering disebut dengan istilah LAN (Local Area Network). Saat ini, kebanyakan LAN berbasis pada teknologi IEEE 802.3 Ethernet menggunakan perangkat switch, yang mempunyai kecepatan transfer data 10, 100, atau $1000 \mathrm{Mbit} / \mathrm{s}$. Selain teknologi Ethernet, saat ini teknologi 802.11b (atau biasa disebut Wi-fi) juga sering digunakan untuk membentuk LAN. Tempat-tempat yang menyediakan koneksi LAN dengan teknologi Wi-fi biasa disebut hotspot.

Setiap komputer juga dapat mengakses sumber daya yang ada di LAN sesuai dengan hak akses yang telah diatur. Sumber daya tersebut dapat berupa data atau perangkat seperti printer. Pada LAN, seorang pengguna juga dapat berkomunikasi dengan pengguna yang lain dengan menggunakan aplikasi yang sesuai.

\section{Aplikasi Pendukung}

\section{- PHP}

PHP singkatan dari PHP adalah Hypertext Preprocessor. PHP merupakan bahasa berbentuk skrip yang ditempatkan dalam server dan diproses di server. Hasilnya yang dikirimkan ke klien, tempat pemakai menggunkan browser. Dengan menggunakan PHP, website akan lebih interaktif dan dinamis. Artinya, ia dapat membentuk tampilan berdasarkan permintaan terkini. Pada prinsipnya PHP mempuyai fungsi yang sama dengan skrip - skrip seperti ASP, Cold Fusion maupun JSP. Kemudahan lain dari PHP adalah mampu berintegrasi dengan berbagai macam database salah satunya MySQL

\section{- MySQL}

Mysql adalah salah satu jenis database server yang sangat terkenal. Kepopulerannya disebabkan MySQL menggunakan SQL sebagai bahasa dasar untuk mengakses databasenya. MySQL bersifat free dengan lisensi GNU General Public License (GPL). Dengan adanya keadaan ini maka anda dapat meggunakan software ini dengan bebas tanpa perlu harus takut dengan lisensi yang ada.MySQL termasuk jenis RDBMS (Relational Database Management System).Itulah sebabnya istilah table, baris, kolom digunakan pada MySQL. Pada MySQL sebuah database mengandung satu atau sejumlah table 


\section{HASIL DAN PEMBAHASAN}

Agar pengembangan aplikasi lebih maksimal, maka perlu dilakukan analisa terhadap aplikasi sangat penting, sehingga sistem yang akan dibangun memiliki acuan dan gambaran umum.

\section{A. Context Diagram}

Context Diagram yang juga merupakan Data Flow Diagram level 0 dari perancangan dan pembuatan sistem gudang yang akan dibuat. Pada context diagram tersebut terdapat empat entitas utama yang terlibat dalam proses sistem yang dibuat ini, yaitu User SAP, Requester,Petugas Gudang dan tim Uji Material Teknik( Jimantek ). Berikut merupakan penjelasan yang telah dibuat oleh penulis.Untuk lebih jelasnyadapat dilihat seperti gambar context diagram berikut

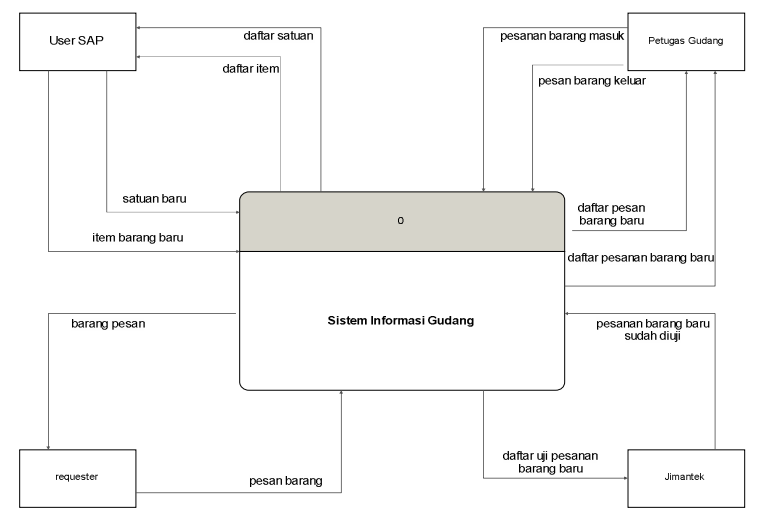

Gambar 1. Context Diagram Sistem Informasi Gudang PLN

Pada gambar diatas user SAP mengelola item barang dan satuan. User SAP dapat membuat item barang dan satuan. Setelah item barang dan satuan di buat, maka petugas gudang sudah dapat melakukan transaksi pesanan barang datang. Transaksi pesanan barang datang merupakan barang yang akan diterima dan dikirim oleh supplier. Pesanan barang tersebut akan dilakukan pengujian kelayakan oleh tim jimantek. Barang yang telah lolos uji akan menjadi pesanan barang masuk dimana barang tersebut masih menunggu kelengkapan secara administratif. Bila administratif pesanan barang tersebut sudah lengkap akan dilakukan proses mutasi ke SAP.

\section{B. Entity Relationship Diagram}

Entity Relationship Diagram merupakan kelanjutan perancangan dari contex diagram dimana di entity relationship diagram berguna untuk mengetahui entitas yang nantinya akan di rekam ke dalam sistem. Untuk lebih jelasnya dapat dilihat gambar berikut

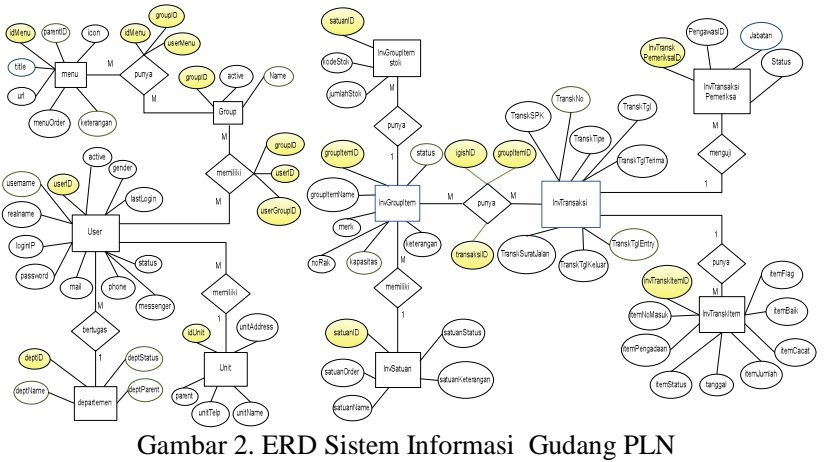

Sedangkan gambar desain arsitektur yang akan diterapkan pada sistem informasi gudang sebagai berikut

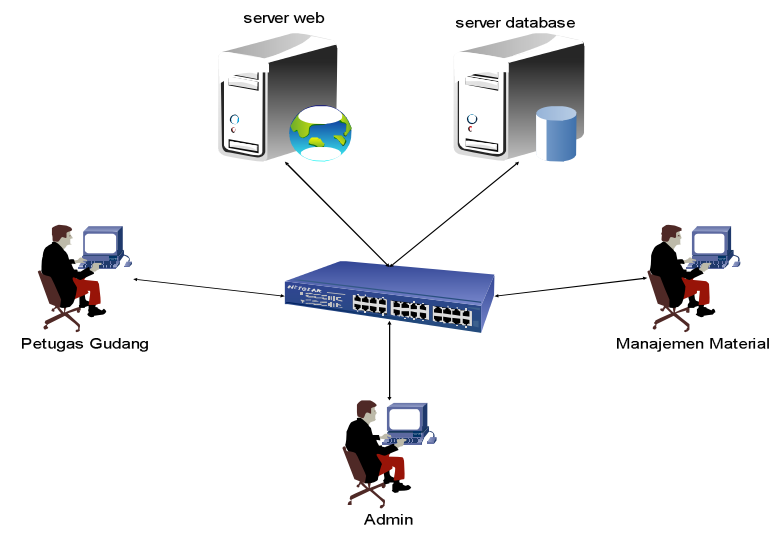

Gambar 3. Desain Arsitektur Sistem Informasi Gudang PLN

C. Implementasi Antar Muka

Pada sub bab ini akan ditunjukkan tampilan antar muka dari aplikasi rekomendasi lokasi rumah yang nantinya akan dengan berinteraksi user.

- Form Login

Berikut tampilan form login, semua user yang terlibat agar bisa menjalankan aplikasi diharuskan login terlebih dahulu.

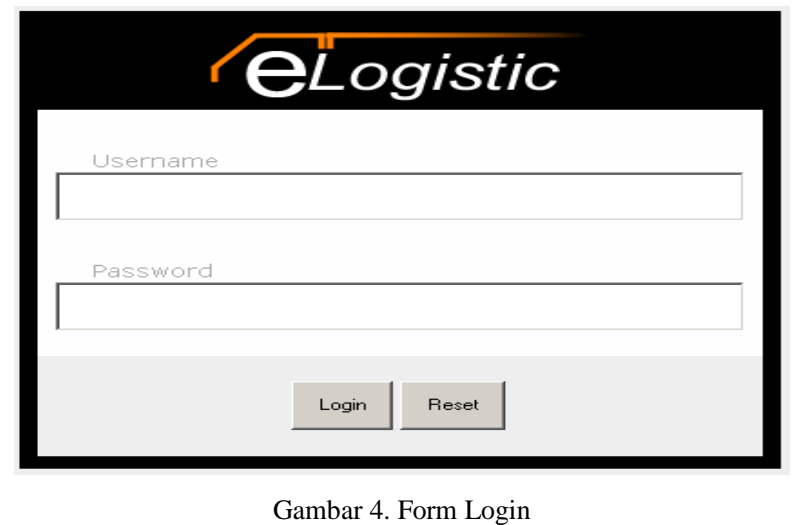

Berikut tampilan form error login apabila user salah password atau kurang input . 


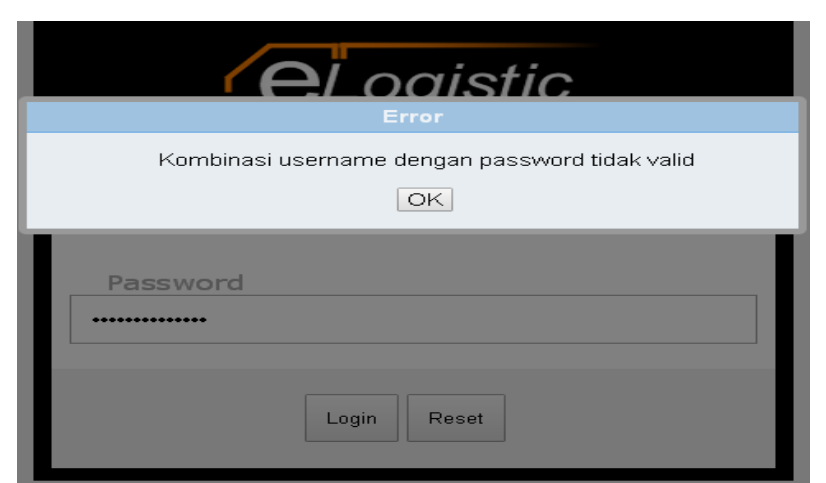

Gambar 5. Form Error Login

\section{- Form Utama}

Berikut tampilan form utama pada aplikasi bila user login sebagai admin. Menu yang ada di admin antara lain Satuan, Item, Barang Masuk, Barang Keluar, Stok Opname dan Laporan.

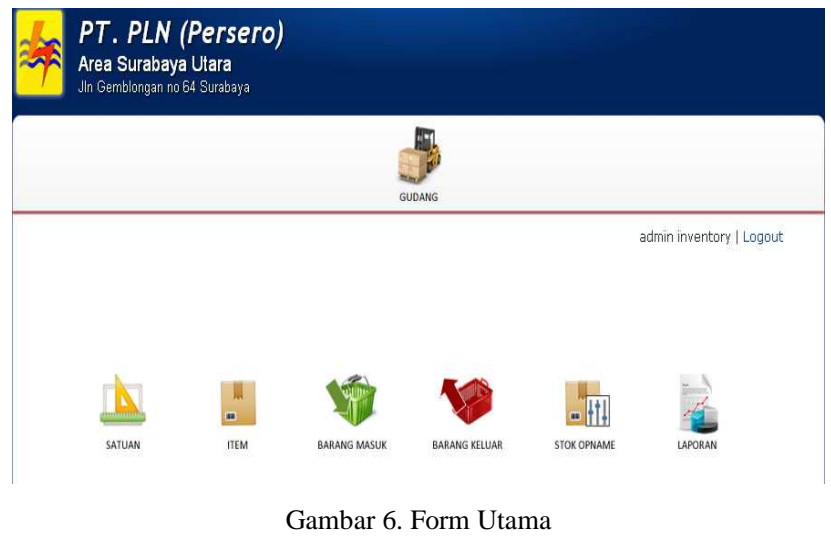

Berikut tampilan form utama pada aplikasi bila user login sebagai user SAP.Pada form ini terdapat fasilitas buat permintaan barang dan saldo stok barang yang terdapat di gudang.
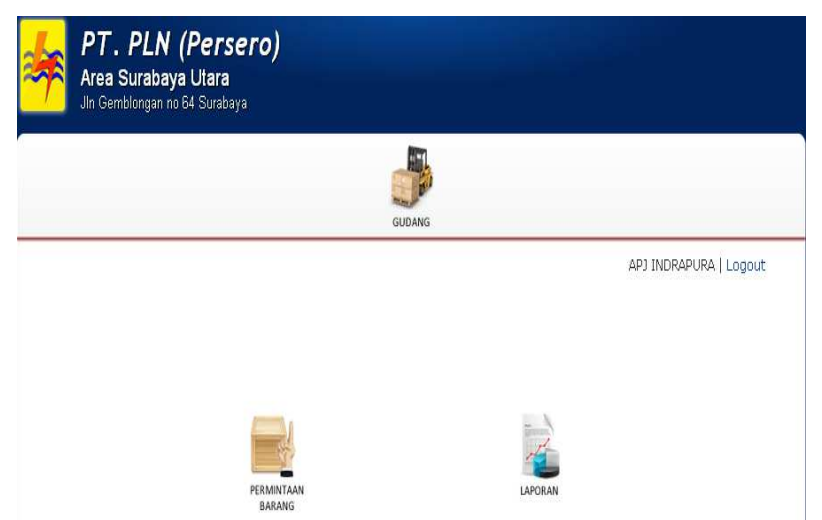

Gambar 7. Form Fungsi Utama

\section{- Form Pengelolaan Satuan}

Berikut merupakan tampilan form pengelolaan satuan. Pada form ini terdapat fasilitas hapus dan tambah satuan baru. Fasilitas ini hanya terdapat pada group admin.

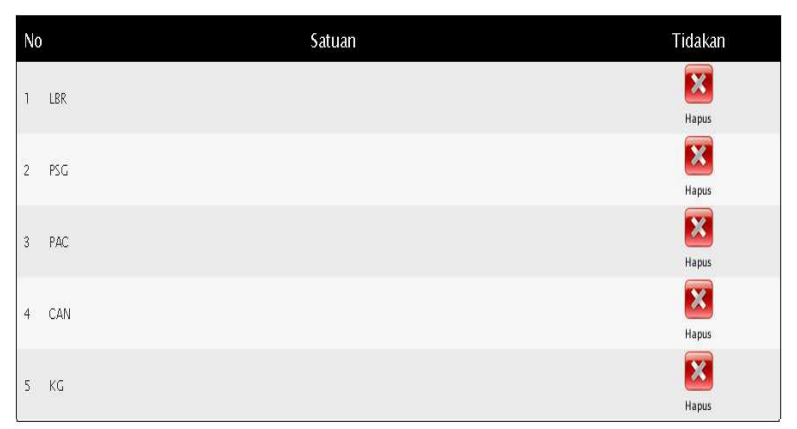

$144 \sqrt{1} \gg M$

Gambar 8. Form Pengelolaan Satuan

\section{- Form Pengeloaan Item}

Berikut merupakan tampilan form list item barang. Pada form ini terdapat fasilitas update, delete dan cetak serta tambah item baru. Fasilitas ini hanya terdapat pada group admin.

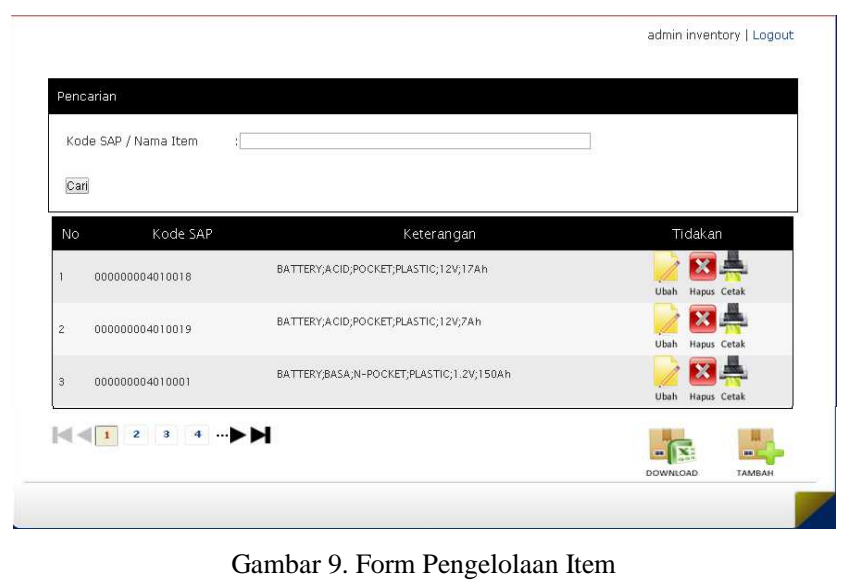

\section{Pengujian}

Untuk pengujian sebuah program yang telah dibangun, maka penulis menggunakan teori white box testing, dengan metode basis path testing. Teori basis path testing adalah suatu metode yang digunakan untuk melakukan pengujian bahwa semua jalur independent terlewati semua, paling tidak minimal suatu jalur harus terlewati sekali. Pengujian basis path pada dasarnya menggunakan flowgraph untuk mengetahui hasil tes pada menu sistem.

- Uji Coba terhadap barang masuk

Pada menu sistem dengan login admin akan diambil satu contoh menu yang paling penting yaitu proses barang masuk gudang. Dimana flowgraph dari menu barang masuk gudang seperti yang tertera pada gambar dibawah ini: 


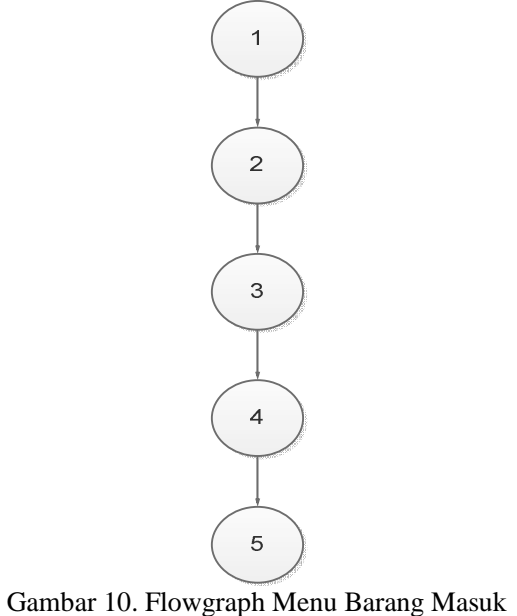

Dengan menggunakan flowgraph, maka didapatkan hasil sebagai berikut:

$$
\begin{aligned}
& \text { Jumlah edge }=4 \text { Jumlah node }=5 \\
& \begin{aligned}
\text { Path } & =(\text { edge }- \text { node })+2 \\
& =(4-5)+2 \\
& =1 \text { path }
\end{aligned}
\end{aligned}
$$

- Uji Coba terhadap barang Keluar

Pada menu sistem dengan login admin akan diambil satu contoh menu yang paling penting yaitu proses barang keluar gudang. Dimana flowgraph dari menu barang keluar gudang seperti yang tertera pada gambar dibawah ini:

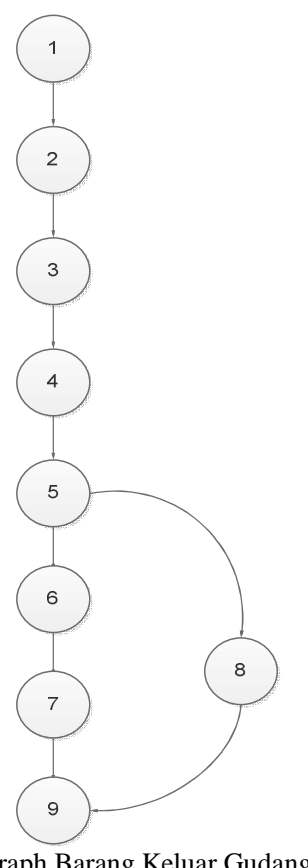

Gambar 11. Flowgraph Barang Keluar Gudang
Dengan menggunakan flowgraph, maka didapatkan hasil sebagai berikut:

$$
\begin{aligned}
& \text { Jumlah edge }=9 \text { Jumlah node }=9 \\
& \begin{aligned}
\text { Path } & =(\text { edge }- \text { node })+2 \\
& =(9-9)+2 \\
& =2 \text { path }
\end{aligned}
\end{aligned}
$$

\section{KESIMPULAN DAN SARAN}

\section{A. Kesimpulan}

Dari hasil perumusan masalah hingga penyelesaian program ini, penulis dapat menarik kesimpulan, antara lain sebagai berikut :

1) Perancangan dan Pembuatan Sistem Gudang studi kasus di PT.PLN (Persero) Area Surabaya Utara ini memudahkan dantransaksi yang terjadi di gudang dalam mengendalikan proses pengadaan barang yang sangat dibutuhkan sesuai administratif gudang untuk mendukung kinerja perusahaan.

2) Sistem ini dapat membantu mempercepat proses pengadaan barang yang disesuaikan dengan jumlah persediaan barang dan kebutuhan barang untuk operasional di lapangan.

B. Saran

Perancangan dan Pembuatan Sistem Gudang di PT PLN APJ Surabaya Utara ini masih jauh dari sempurna. Untuk itu, saran-saran yang dapat penulis berikan antara lain :

1) Pengembangan aplikasi ini dapat diintegrasikan dengan aplikasi lain di dalam institusi, khususnya untuk Business Process Collaboration.

2) Pengembangan aplikasi ini berbasis web mobile agar dapat diakses melalui handphone dan smartphone.

\section{REFERENSI}

[1] Cabral, Sheeri. (2009). MySQL Administrator's Bible (Bible (Wiley)). Indianapolis USA: Wiley Publishing Inc.

[2] Castledin, Earle. (2011). jQuery: Novice to Ninja. Sitepoint.

[3] Gilmore, W. Jason. (2010). Beginning PHP and MySQL: From Novice to Professional. Apress.

[4] Gilmore, W. Jason. (2010). PHP Objects, Patterns and Practice (Expert's Voice in Open Source). Apress.

[5] Kadir, Abdul. (2011). Beginning PHP and MySQL. Yogyakarta: Andi Offset.

[6] Mc Leod, R. J., Schll, G. P. (1995).Sistem Informasi Manajemen. Jakarta: Penerbit Salemba Empat.

[7] Negus, Cristopher. (2011). Fedora Bible 2011 Edition: Featuring Fedora Linux 14. PACKT.

[8] Sakur, Stendy. (2011). PHP 5 Pemrograman Berorientasi Objek Konsep Dan Implementasi. Yogyakarta: Andi Offset. 